\section{BRAZIULIAN JOURNAL}

OF MEDICAL AND BIOLOGICAL RESFARCH

www.bjournal.com.br
ISSN 0100-879X

Volume 44 (7) 606-728 July 2011

BIOMEDICAL SCIENCES

AND

CLINICAL INVESTIGATION

Braz J Med Biol Res, July 2011, Volume 44(7) 694-699

doi: 10.1590/S0100-879X2011007500063

Effect of triiodothyronine on the maxilla and masseter muscles of the rat stomatognathic system

M.V. Mariúba, F. Goulart-Silva, S. Bordin and M.T. Nunes

The Brazilian Journal of Medical and Biological Research is partially financed by

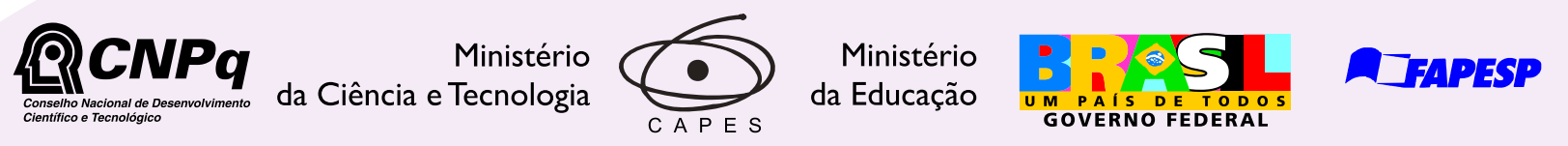

Institutional Sponsors
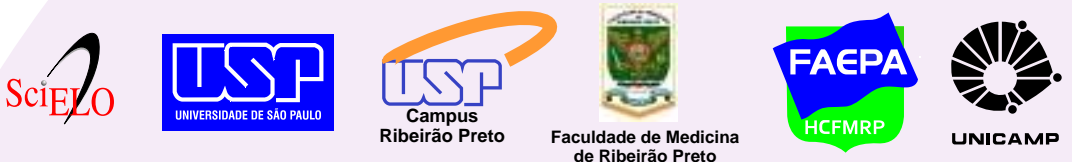

Ф SHIMADZU

GE Healthcare

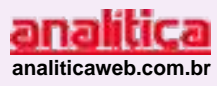

\begin{abstract}
developped by:
\end{abstract}
Thermo
SCIENTIFIC 


\title{
Effect of triiodothyronine on the maxilla and masseter muscles of the rat stomatognathic system
}

\author{
M.V. Mariúba, F. Goulart-Silva, S. Bordin and M.T. Nunes \\ Departamento de Fisiologia e Biofísica, Instituto de Ciências Biomédicas, \\ Universidade de São Paulo, São Paulo, SP, Brasil
}

\begin{abstract}
The maxilla and masseter muscles are components of the stomatognathic system involved in chewing, which is frequently affected by physical forces such as gravity, and by dental, orthodontic and orthopedic procedures. Thyroid hormones (TH) are known to regulate the expression of genes that control bone mass and the oxidative properties of muscles; however, little is known about the effects of TH on the stomatognathic system. This study investigated this issue by evaluating: i) osteoprotegerin (OPG) and osteopontine (OPN) mRNA expression in the maxilla and ii) myoglobin (Mb) mRNA and protein expression, as well as fiber composition of the masseter. Male Wistar rats ( $250 \mathrm{~g})$ were divided into thyroidectomized (Tx) and sham-operated (SO) groups ( $\mathrm{N}=24$ /group) treated with T3 or saline $(0.9 \%)$ for 15 days. Thyroidectomy increased OPG $(\sim 40 \%)$ and OPN ( 75\%) mRNA expression, while T3 treatment reduced OPG ( 40\%) and OPN ( 75\%) in Tx, and both ( $50 \%)$ in SO rats. Masseter $\mathrm{Mb}$ mRNA expression and fiber type composition remained unchanged, despite the induction of hypo- and hyperthyroidism. However, Mb content was decreased in Tx rats even after T3 treatment. Since OPG and OPN are key proteins involved in the osteoclastogenesis inhibition and bone mineralization, respectively, and that $\mathrm{Mb}$ functions as a muscle store of $\mathrm{O}_{2}$ allowing muscles to be more resistant to fatigue, the present data indicate that $\mathrm{TH}$ also interfere with maxilla remodeling and the oxidative properties of the masseter, influencing the function of the stomatognathic system, which may require attention during dental, orthodontic and orthopedic procedures in patients with thyroid diseases.
\end{abstract}

Key words: Triiodothyronine; Osteopontine; Osteoprotegerin; Masseter muscle; Maxilla

\section{Introduction}

The activity of bone cells is regulated by mechanical and hormonal factors (1). Thyroid hormones (TH) are known to participate in bone turnover and their effects have been well established (2).

The expression of proteins such as osteoprotegerin (OPG) and osteopontine (OPN), is reduced by $\mathrm{TH}(3,4)$, in contrast to osteocalcin, alkaline phosphatase and bone morphogenetic proteins, whose expression is increased (5-7). However, the action of $\mathrm{TH}$ is more effective on bone resorption than synthesis, explaining the bone mass loss observed in hyperthyroid states (8).

Bone resorption is associated with decreased OPG and OPN expression. OPG is a member of the transforming growth factor (TGF- $\beta$ ) protein superfamily released from osteoblasts and capable of blocking osteoclastogenesis (9). OPN is an extracellular matrix protein synthesized and released from osteoblasts and osteocytes, responsible for maintaining calcium in the bone matrix, an essential event for mineralization (10). Moreover, it presents a highly conserved arginyl-glycyl-aspartic acid motif that mediates cell attachment to the extracellular matrix via the alpha $\mathrm{V}$ beta 3 integrin (11). Some studies also indicate that OPN is involved in the regulation of the formation and remodeling of mineralized tissue (12). Thus, OPG and OPN are excellent markers for the evaluation of the effect of $\mathrm{TH}$ on bone.

Most of the studies on TH and bones have been conducted on cultured cells and on the appendicular skeleton (13-15). In contrast, few studies have been conducted on the effects of TH on bones of the stomatognathic system, such as the maxilla, that are involved in chewing and subjected to mechanical impact in dental, orthodontic and orthopedic procedures, and therefore could be a potentially important

Correspondence: M.T. Nunes, Departamento de Fisiologia e Biofísica, Instituto de Ciências Biomédicas, USP, 05508-900 São Paulo, SP, Brasil. Fax: +55-11-3091-7285. E-mail: mtnunes@icb.usp.br

Received October 29, 2010. Accepted April 27, 2011. Available online May 13, 2011. Published July 25, 2011. 
subject for investigation.

Skeletal muscles are also known to be targeted by $\mathrm{TH}$. They can be divided into slow or fast type, depending on whether they express type I or type II myosin heavy chain (MHC-I or MHC-II) proteins, respectively, and into oxidative or glycolytic muscles according to their metabolic characteristics (16). Among other proteins, oxidative muscles present a high content of myoglobin (Mb), a protein that functions as a muscle store of $\mathrm{O}_{2}(17,18)$ and as a scavenger of reactive oxygen species and nitric oxide (19), causing them to be more fatigue resistant.

$\mathrm{TH}$ increase $\mathrm{MHC}-\mathrm{Il}$ and $\mathrm{Mb}$ expression in skeletal muscle. This effect is more pronounced in soleus muscle (20), which is considered to be an anti-gravity muscle, as the masseter, which is a component of the stomatognathic system involved in chewing. The masseter is a sexually dimorphic muscle that consists of type II fibers (21), in which the effects of $\mathrm{TH}$ have not been properly evaluated.

In view of these considerations, the objective of the present study was to investigate the effects of TH on OPG and OPN gene expression in the maxilla, as well as on $\mathrm{Mb}$ expression and fiber type in the masseter muscle. This investigation might provide some insight into the influence of $\mathrm{TH}$ specifically on these components of the stomatognathic system, resulting in a better assistance in dental, orthodontic and orthopedic procedures and bucomaxillo-facial surgeries.

\section{Material and Methods}

\section{Animals and treatments}

Male Wistar rats (200-250 g) were obtained from our breeding colony and maintained on rat chow and tap water ad libitum. They were housed in a room kept at a constant temperature of $23 \pm 1{ }^{\circ} \mathrm{C}$ and on a 12-h light/12-h dark schedule (lights on at 7:00 am). Some $(N=24)$ of the animals were subjected to surgical thyroidectomy (Tx rats) after being deeply anesthetized with ketamine and xylazine (100 and $10 \mathrm{mg} / \mathrm{kg}$ body, respectively), and received $0.03 \%$ methylmercaptoimidazole plus $4.5 \mathrm{mM}$ calcium chloride in drinking water for 20 days, while others $(N=24)$ were sham-operated (SO). Both experimental groups were subjected to T3 treatment ( $5 \mu \mathrm{g} / 100 \mathrm{~g}$ body weight, ip) or saline for 15 days and were assigned to the SO, Tx, SO T3, or Tx T3 groups ( $N=12$ /group). The animals were then killed by decapitation and blood was collected for evaluation of total serum T3 concentration with a commercial radioimmunoassay kit (Diagnostics Products Corporation, USA), using a standard curve prepared by adding different concentrations of T3 to iodothyronine-free rat serum. The maxilla and masseter muscles were excised and used for the analysis of OPG and OPN by conventional polymerase chain reaction (PCR), and $\mathrm{Mb}$ gene expression by Northern and Western blotting analysis. The myosin ATPase activity of masseter fibers was determined by histochemistry. Four animals per group were used in each experiment, which was performed three times, for a total of 48 animals.

The experimental protocol followed the ethical principles for animal research adopted by the Brazilian College of Animal Experimentation and was approved by the Ethics Committee for Animal Research of Instituto de Ciências Biomédicas, Universidade de São Paulo.

\section{Reverse transcriptase and PCR}

Amplification of OPG and OPN transcripts. Frozen maxillaries were thawed and subjected to RNA extraction and semi-quantitative RT-PCR analysis. Total RNA was extracted with Trizol reagent (Invitrogen, USA) following manufacturer instructions (22). The first cDNA was synthesized from $2 \mu \mathrm{g}$ RNA using oligo-dT primers and the M-MLV reverse transcriptase kit (Invitrogen). PCR amplification was performed using $1.5 \mu \mathrm{L}$ of each reverse transcription product. The sense and antisense primers used were: GAGGATAAAACGGAGACACAG and GGCTGATCTTCTT CCCAGGC for OPG and GATAGTGCAGAGCGGTCGGA and CAAGCAGTTAGTATTCCTGCTT for OPN. The reaction conditions consisted of denaturation at $95^{\circ} \mathrm{C}$ for $2 \mathrm{~min}$, annealing for $30 \mathrm{~s}$ at $54^{\circ} \mathrm{C}$ for OPG, and $56^{\circ} \mathrm{C}$ for OPN, and amplification at $72^{\circ} \mathrm{C}$ for $30 \mathrm{~s}$. The number of cycles was 35 for OPG and 30 for OPN. The effectiveness of PCR was evaluated by electrophoresis of PCR products on agarose gel stained with ethidium bromide. The bands were analyzed by densitometry using the Scion Image software (ScionCorp, USA). The endogenous control of the PCR assay was the EIFLA constitutive gene whose primer sequence was TGCCGTGGTTCAAGGGATG for sense and GCTGCTTCC ATTGGTGGGTC for antisense; the annealing temperature and number of cycles were $57.7^{\circ} \mathrm{C}$ and 34 , respectively. Results are reported as arbitrary units (AU).

\section{Analysis of $\mathrm{Mb}$ gene expression}

Total masseter RNA was extracted by the method of Chomczynski and Sacchi (23) and subjected to Northern blotting analysis as described previously $(20,24)$. The variability of RNA loading was corrected by membrane rehybridization with a ${ }^{32} \mathrm{P}$-labeled RNA probe specific for $18 \mathrm{~S}$ ribosomal RNA (18S c-rRNA), synthesized by in vitro transcription (Maxi Script in vitro transcription kit, USA). The results are reported as means \pm SEM of the Mb mRNA/18S rRNA ratio.

\section{Analysis of Mb protein expression}

Protein was extracted from the masseter muscle, quantified by the Bradford method (25) (Bio-Rad Protein Assay, Dye Reagent Concentrate, USA) and subjected to Western blotting by the method of dos Santos et al. (20) and Giannocco et al. (24). The blots were analyzed by scanning densitometry and quantified using the Image Master-1D-Pharmacia Biotech SW software (Pharmacia Biotech, Sweden). The data are reported as AU. 
Myosin isoform identification in masseter muscle fibers

This study was performed by determining myofibrillar adenosine triphosphatase (mATPase) activity by histochemistry using a method adapted from Tuxen and Kirkeby (26). Masseter muscle, which had been frozen in isopentane and liquid nitrogen, was cut into $10-\mu \mathrm{m}$ thick histological sections and placed on slides for the analysis of myosin ATPase activity. After fixation with formol-calcium and confirmation of their integrity by toluidine blue staining, the sections were incubated in $30 \mathrm{mM}$ sodium acetate, $0.2 \%$ glacial acetic acid and $16 \mathrm{mM} \mathrm{CaCl}_{2}, \mathrm{pH} 4.3$, or in $50 \mathrm{mM}$ glycine, $50 \mathrm{mM} \mathrm{NaCl}$, $38 \mathrm{mM} \mathrm{CaCl}_{2}$ and $47 \mathrm{mM} \mathrm{NaOH}, \mathrm{pH} 10.3$, solutions for 10 min at room temperature, followed by incubation with glycine buffer containing $3 \mathrm{mM}$ ATP for $35 \mathrm{~min}$ at room temperature. The sections were washed, mounted with glycine jelly, and visualized under a Nikon microscope (Nikon Eclipse E 1000, USA). The masseter muscle fiber type was then classified and the images were captured with the Image Pro-Plus software (Media Cybernetic, USA).

\section{Statistical analysis}

Data are reported as means \pm SEM and the level of significance was set at $5 \%(P<0.05)$. Statistical analysis was performed by two- or three-way analysis of variance (ANOVA) followed by the Bonferroni post-test.

\section{Results}

The effectiveness of Tx and of T3 treatment was confirmed by determining the serum T3 concentration and body weight of the animals. As expected, Tx rats showed reduced serum T3 levels and body weight. Tx and SO rats treated with T3 for 15 days presented increased serum T3 concentrations, with no changes in body weight (Table 1).

\section{Effect of thyroid hormone on the OPG and OPN gene expression in the maxilla}

The effect of TH on OPG mRNA expression in the maxilla is presented in Figure 1A, which shows that Tx induced a $40 \%$ increase in OPG mRNA content (vs SO), and that $\mathrm{T} 3$ treatment reduced it to SO levels. Euthyroid (SO) rats subjected to T3 treatment also presented reduced OPG mRNA content ( $60 \%)$.

Figure 1B shows that OPN mRNA levels are regulated

Table 1. Effect of triiodothyronine (T3) on body weight and serum T3 levels of sham-operated and thyroidectomized rats.

\begin{tabular}{lcccr}
\hline & SO & SO T3 & Tx & Tx T3 \\
\hline Body weight $(\mathrm{g})$ & & & & \\
Day 0 & $298.54 \pm 13.22$ & $308 \pm 6.37$ & $236.91 \pm 10.56$ & $236.8 \pm 8.58$ \\
Day 15 & $303.97 \pm 12.65$ & $301.35 \pm 6.88$ & $219.82 \pm 4.88$ & $238.15 \pm 6.12$ \\
Total T3 serum concentration $(\mathrm{ng} / \mathrm{mL})$ & $0.35 \pm 0.03$ & $0.61 \pm 0.19^{*}$ & $0.17 \pm 0.01^{\star \# \#}$ & $0.56 \pm 0.03^{\#}$ \\
\hline
\end{tabular}

Data are reported as means \pm SEM. SO = sham-operated rats; SO + T3 = sham-operated rats treated with T3; $\mathrm{Tx}=$ thyroidectomized rat; $\mathrm{T} x+\mathrm{T} 3=$ thyroidectomized rat treated with $\mathrm{T} 3$. Body weight data were analyzed by three-way ANOVA and serum T3 values were analyzed by two-way ANOVA. *P $<0.05$ vs SO, $\mathrm{P}<0.05$ vs SO $+\mathrm{T} 3,{ }^{\#} \mathrm{P}<0.05$ vs $\mathrm{Tx}+\mathrm{T} 3 . \mathrm{N}=9$ to 13 rats per group.
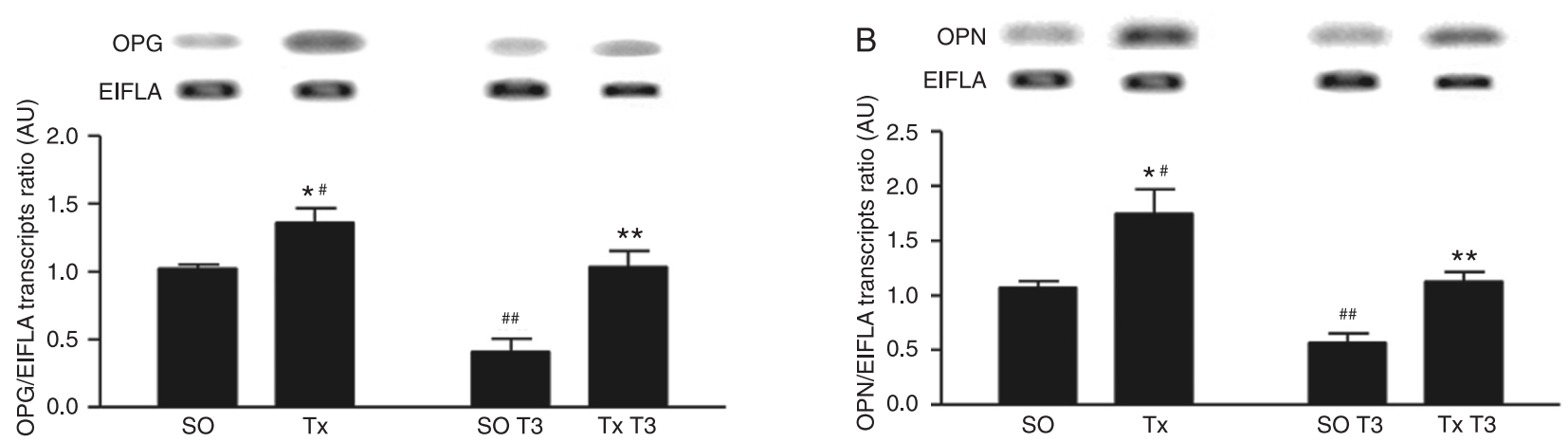

Figure 1. Triiodothyronine (T3) decreases osteoprotegerin (OPG) and osteopontine (OPN) mRNA expression in the rat maxilla. Panels $A$ and $B$ show the OPG and OPN mRNA content, respectively, in the maxilla of sham-operated (SO), thyroidectomized (Tx), shamoperated T3-treated (SO T3), and Tx rats chronically treated with T3 (Tx T3). The T3 dose used was $5 \mu \mathrm{g} / 100 \mathrm{~g}$ body weight for 15 days. Typical representative images of OPG, OPN and EIFLA gene expression are given at the top of the panels. Three experiments were performed with 4 animals per group $(N=48)$. Data are reported as means $\pm S E M$, expressed in arbitrary units $(A U)$, and were analyzed by two-way analysis of variance (ANOVA), followed by the Bonferroni post-test. ${ }^{*} \mathrm{P}<0.0001$ vs SO; ${ }^{*} \mathrm{P}<0.0001$ vs SO T3; $\# \mathrm{P}<0.0001$ vs Tx T3; \#\# $<0.0001$ vs SO. 
by $\mathrm{TH}$ in a similar fashion as OPG, since Tx increased significantly OPN gene expression and T3 treatment restored it to SO levels. T3 treatment was shown to reduce OPN mRNA content in SO rats as well.

\section{Effect of thyroidectomy on Mb mRNA and protein expression in masseter muscle}

The effect of $\mathrm{TH}$ on masseter Mb mRNA and protein expression is shown in Figure $2 A$ and $B$, respectively. Tx
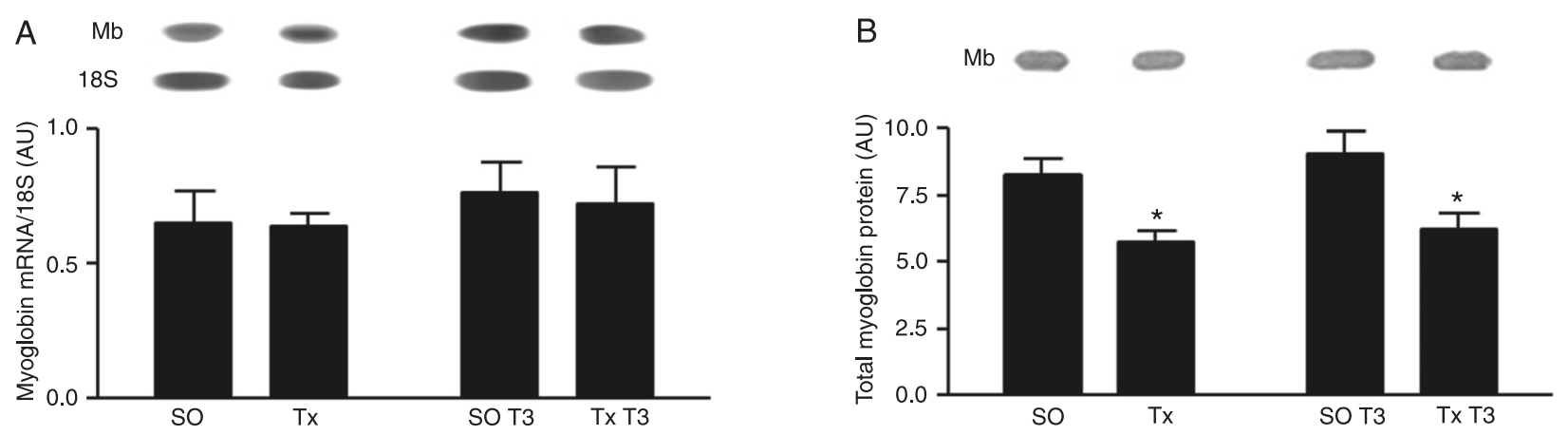

Figure 2. Effect of thyroidectomy on myoglobin (Mb) mRNA and protein expression in rat masseter muscle. Panels $A$ and $B$ show the Mb mRNA and protein content, respectively, in masseter muscle of sham-operated (SO), thyroidectomized (Tx), sham-operated T3treated (SO T3), and Tx rats chronically treated with T3 (Tx T3). The T3 dose used was $5 \mu \mathrm{g} / 100 \mathrm{~g}$ body weight, for 15 days. Typical representative blots of $\mathrm{Mb}$ and $18 \mathrm{~S}$ transcripts $(\mathrm{A})$ and $\mathrm{Mb}$ protein $(\mathrm{B})$ are given at the top of the panels. Three experiments were performed with 4 animals per group $(N=48)$. Data are reported as means $\pm S E M$, expressed in arbitrary units $(A U)$, and were analyzed by two-way analysis of variance (ANOVA), followed by the Bonferroni post-test. ${ }^{*} \mathrm{P}<0.05$ vs SO and SO T3.

A

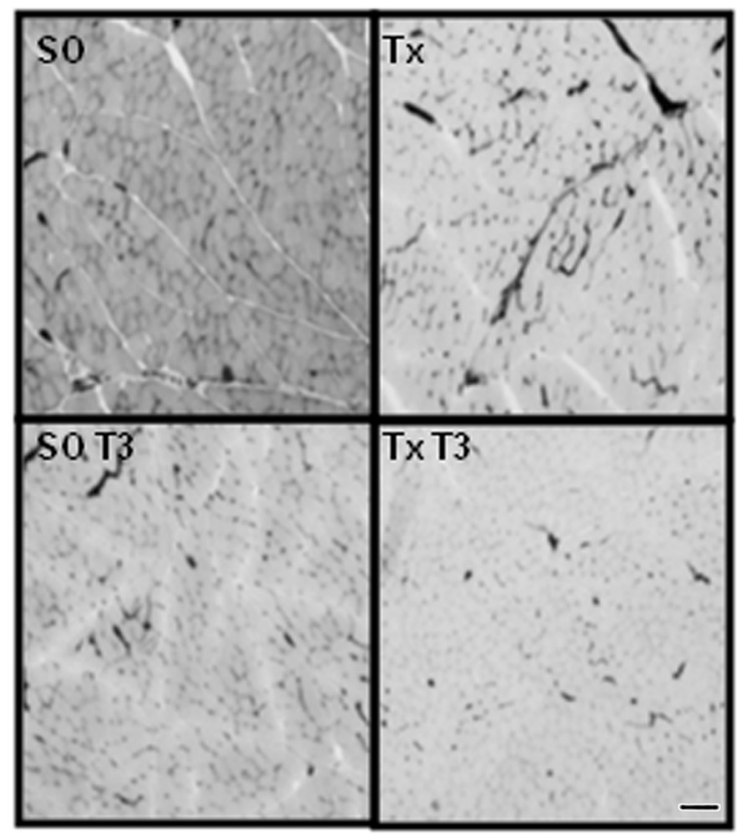

B

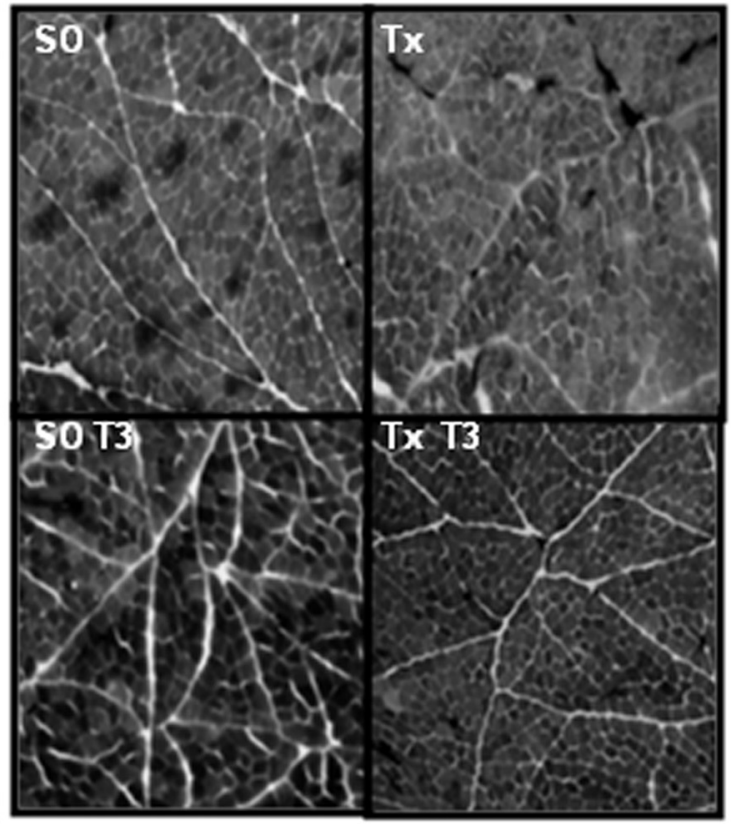

Figure 3. Effect of triiodothyronine (T3) on masseter muscle fiber types. Serial cross-sections of the masseter muscle from sham-operated (SO), thyroidectomized (Tx), sham-operated T3-treated (SO T3), and Tx rats chronically treated with T3 (Tx T3) illustrating the histochemical stains for myosin ATPase activity. The amount of T3 used was $5 \mu \mathrm{g} / 100 \mathrm{~g}$ body weight, for 15 days. Fiber types are identified as type I and II based on myosin ATPase histochemistry using different preincubation at different pH, namely 4.3 (Panel A) and 10.3 (Panel B). Type II fibers show myosin ATPase activity at alkaline $\mathrm{pH}$ (alkaline-resistant fibers: dark fibers) and absence of it at acid pH (acid-labile fibers: light fibers). Five animals per group were used. Bars $=100 \mu \mathrm{m}$. 
rats did not show any alteration in Mb mRNA expression, even after T3 treatment. The same occurred with the SO animals subjected to T3 treatment (Figure 2A). However, Mb protein expression was decreased in Tx rats and was not altered by T3 treatment. T3 treatment also did not change the $\mathrm{Mb}$ protein content in the masseter muscle of SO rats (Figure 2B).

\section{Effect of thyroid hormone on masseter muscle fiber types}

Myosin ATPase activity was determined in masseter muscle sections of control (SO) and Tx rats subjected or not to chronic T3 treatment (SO T3; Tx T3). The results are shown in Figure 3, in which Panels A and B illustrate the myosin ATPase activity of the fibers that were pre-incubated at acid or alkaline $\mathrm{pH}$, respectively. It was observed that myosin ATPase activity was absent in A, and present in $B$, confirming that the masseter muscle presents a higher expression of type II fibers, which are supposed to be fasttwitch, acid-labile and alkaline-resistant fibers. At pH 4.3 and $\mathrm{pH}$ 10.3, this pattern of myosin ATPase activity expression was not changed by thyroidectomy and T3 treatment.

\section{Discussion}

In the present study, we used the maxilla and masseter muscles to evaluate the effects of TH on the stomatognathic system. We have shown that thyroidectomy increased the expression of OPG and OPN genes and that T3 administration for 15 days decreased it, clearly indicating that $\mathrm{TH}$ exerts a major effect on maxilla resorption. These findings support literature data indicating a negative regulation of these genes by TH (27-29), and should be considered when hyperthyroid patients are subjected to surgical, orthodontic and orthopedic procedures.

In fact, local OPG application decreases the movement of the teeth during orthodontic manipulations (30), whereas $\mathrm{TH}$ have been shown to enhance tooth movement (31). These data suggest a relationship between OPG and TH, which had not been previously investigated. The results of the present study suggest a decrease of OPG and OPN gene expression during hyperthyroidism. This may explain the increase in tooth movement after TH administration, since they induce loss of bone mass.

Concerning the masseter, which is an anti-gravity muscle, as expected, we observed a higher expression of type

\section{References}

1. Zofkova I. Hormonal aspects of the muscle-bone unit. Physiol Res 2008; 57 (Suppl 1): S159-S169.

2. Bassett JH, O'Shea PJ, Sriskantharajah S, Rabier B, Boyde A, Howell PG, et al. Thyroid hormone excess rather than thyrotropin deficiency induces osteoporosis in hyperthyroidism. Mol Endocrinol 2007; 21: 1095-1107.
II fibers (26). This contrasts with other anti-gravity muscles such as the soleus, which present a predominance of type I fibers and higher Mb expression, and where $\mathrm{TH}$ increase the expression of type II fibers and $\mathrm{Mb}(20)$.

In the present study, the fiber type and $\mathrm{Mb}$ content of the masseter muscle were unchanged by T3 administration. Even though the methodology employed to classify the fibers has certain limitations (32), the results obtained by T3 treatment were somehow expected, since T3 is known to increase type II fibers in skeletal muscle (33). However, thyroidectomy was shown to reduce Mb content and T3 treatment was unable to restore it to control levels. It is very interesting that masseter muscle has been shown to be refractory to excess $\mathrm{TH}$ administration, even though it presented a decrease in the Mb protein content, in hypothyroidism, which could result from the reduced metabolic rate observed in this condition (34). It is possible that its diverse embryological origin might account for this result. In addition, the masseter is a sexually dimorphic muscle, and this kind of muscle has been shown to present low expression of $\mathrm{TH}$ receptors or a reduced affinity of $\mathrm{TH}$ receptors for $\mathrm{T} 3$ $(35,36)$, which could explain its insensitivity to TH administration. In fact, no differences in fiber types were observed in masseter muscle after either hypo- or hyperthyroidism induction, a fact that supports our hypothesis.

Even though further studies are needed to define better the relationship between $\mathrm{TH}$ and masseter muscle, it is possible to infer that chewing is not affected by $\mathrm{TH}$, since the main muscle involved in this function, the masseter, is supposed to be insensitive to excess TH. Nevertheless, the maxilla was shown to be strongly affected by $\mathrm{TH}$ since chronic T3 treatment led to a decrease in OPG and OPN gene expression, indicating that bone resorption was taking place. This would require more attention on the part of the dental surgeon during tooth extraction, bucco-maxillo-facial surgeries, and during frequently performed orthodontic and orthopedic procedures.

\section{Acknowledgments}

The authors thank Dr. Anselmo Sigari Moriscot for assistance with the morphological analysis and Leonice Lourenço Poyares for excellent technical assistance. Research supported by CNPq (\#305659/2009-0). F. Goulart-Silva is the recipient of a FAPESP fellowship (\#2008/56446-9).

3. Kanatani M, Sugimoto T, Sowa H, Kobayashi T, Kanzawa M, Chihara K. Thyroid hormone stimulates osteoclast differentiation by a mechanism independent of RANKL-RANK interaction. J Cell Physiol 2004; 201: 17-25.

4. Ohishi K, Ishida H, Nagata T, Yamauchi N, Tsurumi C, Nishikawa $S$, et al. Thyroid hormone suppresses the differen- 
tiation of osteoprogenitor cells to osteoblasts, but enhances functional activities of mature osteoblasts in cultured rat calvaria cells. J Cell Physiol 1994; 161: 544-552.

5. Kanno Y, Ishisaki A, Yoshida M, Nakajima K, Tokuda H, Numata $\mathrm{O}$, et al. Adenylyl cyclase-cAMP system inhibits thyroid hormone-stimulated osteocalcin synthesis in osteoblasts. Mol Cell Endocrinol 2005; 229: 75-82.

6. Akalin A, Colak O, Alatas O, Efe B. Bone remodelling markers and serum cytokines in patients with hyperthyroidism. Clin Endocrinol 2002; 57: 125-129.

7. Lassova L, Niu Z, Golden EB, Cohen AJ, Adams SL. Thyroid hormone treatment of cultured chondrocytes mimics in vivo stimulation of collagen $X$ mRNA by increasing BMP 4 expression. J Cell Physiol 2009; 219: 595-605.

8. Sato K. [Graves' disease and bone metabolism]. Nippon Rinsho 2006; 64: 2317-2322.

9. Kobayashi Y, Udagawa N, Takahashi N. Action of RANKL and OPG for osteoclastogenesis. Crit Rev Eukaryot Gene Expr 2009; 19: 61-72.

10. Sodek J, Ganss B, McKee MD. Osteopontin. Crit Rev Oral Biol Med 2000; 11: 279-303.

11. McKee MD, Nanci A. Osteopontin at mineralized tissue interfaces in bone, teeth, and osseointegrated implants: ultrastructural distribution and implications for mineralized tissue formation, turnover, and repair. Microsc Res Tech 1996; 33: 141-164.

12. Denhardt DT, Guo X. Osteopontin: a protein with diverse functions. FASEB J 1993; 7: 1475-1482.

13. Capelo LP, Beber EH, Fonseca TL, Gouveia CH. The monocarboxylate transporter 8 and L-type amino acid transporters 1 and 2 are expressed in mouse skeletons and in osteoblastic MC3T3-E1 cells. Thyroid 2009; 19: 171-180.

14. Freitas FR, Capelo LP, O'Shea PJ, Jorgetti V, Moriscot AS, Scanlan TS, et al. The thyroid hormone receptor beta-specific agonist GC-1 selectively affects the bone development of hypothyroid rats. J Bone Miner Res 2005; 20: 294-304.

15. Yao M, Dooley PC, Schuijers JA, Grills BL. The effects of hypothyroidism on nerve growth factor and norepinephrine concentrations in weight-bearing and non-weight-bearing bones of rats. J Musculoskelet Neuronal Interact 2004; 4: 319-324.

16. Pette D, Staron RS. Myosin isoforms, muscle fiber types, and transitions. Microsc Res Tech 2000; 50: 500-509.

17. Strand I, Strand PO, Christensen EH, Hedman R. Myohemoglobin as an oxygen-store in man. Acta Physiol Scand 1960; 48: 454-460.

18. Wittenberg JB, Wittenberg BA. Myoglobin function reassessed. J Exp Biol 2003; 206: 2011-2020.

19. Kreutzer $U$, Jue T. Investigation of bioactive NO-scavenging role of myoglobin in myocardium. Pflugers Arch 2006; 452: 36-42.

20. dos Santos RA, Giannocco G, Nunes MT. Thyroid hormone stimulates myoglobin expression in soleus and extensorum digitalis longus muscles of rats: concomitant alterations in the activities of Krebs cycle oxidative enzymes. Thyroid 2001; 11: 545-550.
21. Eason JM, Schwartz GA, Pavlath GK, English AW. Sexually dimorphic expression of myosin heavy chains in the adult mouse masseter. J Appl Physiol 2000; 89: 251-258.

22. Wilfinger WW, Mackey K, Chomczynski P. Effect of $\mathrm{pH}$ and ionic strength on the spectrophotometric assessment of nucleic acid purity. Biotechniques 1997; 22: 474-481.

23. Chomczynski P, Sacchi N. Single-step method of RNA isolation by acid guanidinium thiocyanate-phenol-chloroform extraction. Anal Biochem 1987; 162: 156-159.

24. Giannocco G, DosSantos RA, Nunes MT. Thyroid hormone stimulates myoglobin gene expression in rat cardiac muscle. Mol Cell Endocrinol 2004; 226: 19-26.

25. Bradford MM. A rapid and sensitive method for the quantitation of microgram quantities of protein utilizing the principle of protein-dye binding. Anal Biochem 1976; 72: 248-254.

26. Tuxen A, Kirkeby S. An animal model for human masseter muscle: histochemical characterization of mouse, rat, rabbit, cat, dog, pig, and cow masseter muscle. J Oral Maxillofac Surg 1990; 48: 1063-1067.

27. Xiang GD, Sun HL, Zhao LS, Hou J, Yue L. [Changes in plasma concentrations of osteoprotegerin before and after levothyroxine replacement therapy in hypothyroid patients]. Zhonghua Yi Xue Za Zhi 2007; 87: 2121-2125.

28. Guang-Da X, Hui-Ling S, Zhi-Song C, Lin-Shuang Z. Alteration of plasma concentrations of OPG before and after levothyroxine replacement therapy in hypothyroid patients. J Endocrinol Invest 2005; 28: 965-972.

29. Liou YM, Chang LY, Liaw JM, Jiang MJ. Osteopontin gene expression in the aorta and the heart of propylthiouracil-induced hypothyroid mice. J Biomed Sci 2005; 12: 869-880.

30. Dunn MD, Park CH, Kostenuik PJ, Kapila S, Giannobile WV. Local delivery of osteoprotegerin inhibits mechanically mediated bone modeling in orthodontic tooth movement. Bone 2007; 41: 446-455.

31. Tyrovola JB, Spyropoulos MN. Effects of drugs and systemic factors on orthodontic treatment. Quintessence Int 2001; 32: 365-371.

32. Staron RS, Kraemer WJ, Hikida RS, Fry AC, Murray JD, Campos GE. Fiber type composition of four hindlimb muscles of adult Fisher 344 rats. Histochem Cell Biol 1999; 111: 117-123.

33. Nunes MT, Bianco AC, Migala A, Agostini B, Hasselbach W. Thyroxine induced transformation in sarcoplasmic reticulum of rabbit soleus and psoas muscles. Z Naturforsch C 1985; 40: 726-734.

34. Weitzel JM, Iwen KA, Seitz HJ. Regulation of mitochondrial biogenesis by thyroid hormone. Exp Physiol 2003; 88: 121128.

35. d'Albis A, Chanoine C, Janmot C, Mira JC, Couteaux R. Muscle-specific response to thyroid hormone of myosin isoform transitions during rat postnatal development. Eur $J$ Biochem 1990; 193: 155-161.

36. Izumo S, Nadal-Ginard B, Mahdavi V. All members of the MHC multigene family respond to thyroid hormone in a highly tissue-specific manner. Science 1986; 231: 597-600. 